\title{
Digital Disease Tracker v1.X, a mobile application to monitor the health of Mexican schools
}

\author{
Mariángel García, Jesús Enrique Luna, Dorian Jesús Morales, Armando \\ Rivera, Yazmín Magallanes
}

Published: 30 November 2021

\begin{abstract}
After the recent return to face-to-face classes in schools in Mexico, after they were suspended due to the COVID-19 pandemic, it became clear that it was necessary to control students' health better. For this reason, we proposed the design of the Digital Disease Tracker, a system that works on mobile devices applying the UserCentered Design approach. Our system aims to allow a more complete, clear, and updated record of the student community. With this registry, educational institutions can better know the status of their students and know the level of risk in that institution to take measures to reduce it. With the evaluation carried out, we observed that the application is useful, and it is also an easy-to-use tool, which allows most users to use it without problems. It is essential to use these types of registries to help control the spread of various diseases in Mexico.
\end{abstract}

\section{Keywords:}

Health system control; Mobile application; Contagious diseases; COVID-19 pandemic; Mexican schools; User-Centered Design.

\section{Introduction}

Since their invention, computers have had the purpose of systematizing and operating large amounts of information. Data are considered their raw material and, for that reason, have been taking much relevance in all aspects of human life [3].

In 2019, the world faced a health crisis that has had a significant and life-changing impact on all aspects of life. The spread of the SARS-CoV-2 virus has not only demonstrated that there are major deficiencies in public health but has also presented a challenge to science because it is a fight against the clock to eradicate this deadly virus [5]. As the World Bank mentioned, "COVID-19 has created the worst crisis for education and learning in a century" [11]. The information generated by the COVID 19 attack, and its variants is updated moment by moment. Although mathematical models predict the regions with the highest incidence, age groups, and social strata; these could not be implemented without innovative computer systems that concentrate

García, Mariángel., Luna, Jesús Enrique., Morales, Dorian Jesús., Rivera, Armando., Magallanes, Yazmín.

Universidad de las Américas Puebla

Puebla, Mexico

\{mariangel.garciato, jesus.lunapz, dorian.moralessz, armando.riveraco, yazmin.magallanes\}@udlap.mx quantitative and qualitative variables. To this end, we propose the use of the Digital Disease Tracker, a mobile application that allows educational centers to have better control of the health status of students and teachers, showing the record of the vaccinations they have received, illnesses, or if they are following any treatment. The Digital Disease Tracker will also make it possible to anonymously report if a user has been exposed to another person suffering from an easily transmissible disease. All the symptoms are validated by a medical specialist who will confirm the diagnosis and determine the disease's treatment and transmission capacity. Thus, from this, teachers will be able to know the health status of students and the authenticity of this information.

\section{Related work}

Before the pandemic, health-focused applications had already been developed due to the spread of the SARS-COV-2 virus. An example is the Health application created by Apple Inc., which allows recording information on physical activity, anthropometric measurements, nutrition, hours of sleep, among others [8]. The Health application works best with an Apple Watch device. In this case, the user can keep a complete record that includes, in addition to the aforementioned information, their vital signs, breathing, heart rate, blood oxygen measurement, and an electrocardiogram. Even with all these features, the COVID-19 pandemic has shown that the systems implemented so far are not enough.

Before the vaccination process, the first challenge that humanity has faced was to stop and reduce the number of COVID 19 infections. In this sense, Apple and Google using Bluetooth technology, designed a system to identify infected people by monitoring, recording, and mapping their place of residence and hiding their personal information [10]. Kondylakis (2020) mentions the StudentLife application, focused on assessing depression and anxiety in college students to determine if there was a change in users' behavior and mental health because of COVID-19 [7]. Annis et al. (2020), report the development of a remote monitoring system for patients; the usefulness of this system lies in reducing waiting time in calls to clinics and promoting better monitoring of patients avoiding clinical examination in a hospital [2]. The mobile application that we propose, unlike those mentioned above, is focused on measuring the exposure of all diseases considered highly contagious, e.g., measles, influenza, smallpox, etc. Likewise, said application will control and record the vaccines, the medical record, and other essential functionalities for the student, such as a record of absence from classes due to illness and announcements from the teacher to their students. 


\section{Methodology}

The project was carried out following the User-Centered Design (UCD) approach, a cyclical process. In this process, the users drive the design decisions, in addition to the product objectives. According to ISO 13407 [6], the first step was to understand and specify the context of use. For this step, a meeting was held with the team members to look for current problems and think about possible solutions. Therefore, we concluded that the application would be focused on the student community due to the return to classes in Mexico so that the educational institution could have clear and accurate control over the health record of their students. We decided to work with the Miro ${ }^{1}$ tool to have a better organization. Miro is a handy platform for teamwork; it allowed us to collaborate visually with sticky notes, documents, mockups, among others. So, in this tool, we posted the wireframes of the interfaces of the mobile application.

We specified the requirements during the second stage and identified the objectives to satisfy the users' needs. Our propose was that the user interface should be simple, aesthetically pleasing to the eye, intuitive, and with the necessary elements so that the critical information is in the right place. According to [1], the interface plays a fundamental role in whether the application is competitive or not.

The third step was to produce design solutions. For this, the decision we made was to design the Digital Disease Tracker for iOS and Android ecosystems, respecting the environment of each one. An advantage with iOS is that it "integrates tightly with other programming frameworks and technologies, such as Apple Pay, HealthKit, and ResearchKit, allowing you to build incredibly powerful applications" [9]. Considering the application's functionalities, each team member designed the proposals for the interfaces to have different ideas and subsequently created a single interface that combines the best ideas of all.

\section{Design}

The application is focused on students ranging from elementary to high school level; however, it was essential to establish the different user profiles that the application will have. These users are shown in Table 1.

Table 1. Description of user profiles

\begin{tabular}{|l|l|}
\hline User profile & Description \\
\hline $\begin{array}{l}\text { Students with } \\
\text { access to a } \\
\text { phone }\end{array}$ & $\begin{array}{l}\text { The student manages his profile. The } \\
\text { student has access to more options and } \\
\text { allows the use of viral disease tracking. A } \\
\text { teacher or doctor validates the symptoms or } \\
\text { illnesses that the student may have. }\end{array}$ \\
\hline $\begin{array}{l}\text { Students } \\
\text { without access } \\
\text { to a phone }\end{array}$ & $\begin{array}{l}\text { The parent or guardian administers the } \\
\text { medical record. The student can log in using } \\
\text { a printed QR code. }\end{array}$ \\
\hline Professors & $\begin{array}{l}\text { Allows the view of the list of the assigned } \\
\text { students. }\end{array}$ \\
\hline
\end{tabular}

\subsection{User Interfaces}

We consider three types of users for the design of the interfaces, as shown in Table 1. The first user is a student who does have his cell

${ }^{1}$ The link of out virtual whiteboard on Miro tool is: https://miro.com/app/board/o9J_lyFZ2YU=/

phone. The learner is responsible for managing their record and has access to their QR code identification quickly and easily. A doctor must validate the symptoms or medical processes that the student carries out. A teacher can also do it on certain occasions as long as the student has a medical voucher. The second user is a student who does not have his own cell phone. For this reason, a parent or guardian must be in charge of managing their profiles. The designated guardian will be in charge of filling out the entire medical record and keeping all of their medical records manually. Since the QR code helps the student be more easily identified, it can be printed out so that the student can carry their identification code with them if they need it. The third user could be either a teacher or a principal. A teacher can have different levels of permission; for example, he may only be able to see the current status of his students who were assigned only to him for his subject. A principal can see the status of all the students within that educational institution.

The registration process is carried out as shown in Figure 1. As it is the first time the user enters, they must select the type of user, regardless of whether they already have a previously registered user. Three different buttons are displayed, which say: "I am a student," "I am a family guy," and "I am a professor." If the user selects any of the three options, the interface goes to the log-in window. In this interface, the user could already be registered with his Unique Population Registration Code (CURP, for its acronym in Spanish) and password, or else he can create a new one.

When the user enters the platform, he has access to a home screen, which varies depending on the type of user. In the case of being a student who has a mobile phone, the window that it will show will be like Figure 2, where the student has direct access to different links. The links included are the attendance list, in which a calendar is displayed, marking the days that the student has attended school without any problems or those that have been absent but have been excused by medical issues. School announcements, such as suspension notices or essential reminders, can also be given in the home window. In the same way, news and recommendations provided by the World Health Organization are shown. In the upper-right part, there is a notifications button. These notifications can be messages that a teacher has sent directly to the student, publication of new announcements, or suggestions provided by the same system depending on their activity or greeting status.

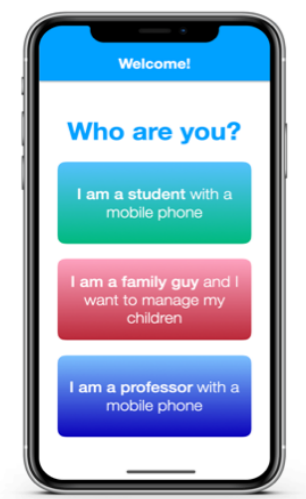

Figure 1. The first step to enter the application is to select the type of user when (only the first time).

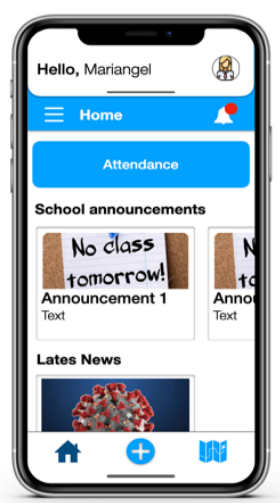

Figure 2. Main screen for a student with a mobile phone where he can see announcements and the latest news. 
On the home screen, a bar is displayed at the top, which, when scrolled down, shows the user identification QR code. The code changes color depending on the user's status. That is, if it is green, it will indicate that it is low risk, which means that the user has not been exposed to such crowded places and that the user has their complete vaccination scheme. If it is orange, the user must take precautions because he has been in crowded areas with a high risk of contagion due to a disease or that by the time that some of their vaccines have passed, they are losing their effectiveness. Red will be a high risk, so it is not recommended that the student enters the institution since it is likely to infect his colleagues with a contagious disease. It is worth mentioning that when it is scanned, the teacher will be given more detailed information about the reason for the color. Likewise, the user can print their code if they wish, this to be able to identify themselves in case of not being able to take their device to school or, for some reason, it is necessary to share this code.

Each user can access their profile by touching their photo. This allows them to see their information in more detail, as shown in Figure 3. Their profile photo, name, age, and access to their Medical ID are headed. The Medical ID contains essential user information such as blood type, allergies, emergency contacts, weight, and height. Below the header is information about the record of the different vaccines that the person has received, the medical check-ups, and the treatments they are taking. This is shown in a small list of two elements, but if the user wants to see the complete list, it is enough with a click on the "plus" button, and the following ten items will be shown; if there are still more items without showing the "plus" button it will still be available. Notices of upcoming events are also shown, such as the following vaccines that the user should receive due to the loss of efficacy of the vaccine due to the time that has elapsed if this is the case.

By keeping a clear and complete medical record on the cell phone, better tracking can be done thanks to Bluetooth and GPS built into most phones today. In this way, the most traveled areas by users suffering from a contagious disease are anonymously recorded. These areas are shown on a map provided either by Apple Maps on iOS or by Google Maps on Android, as shown in Figure 4.

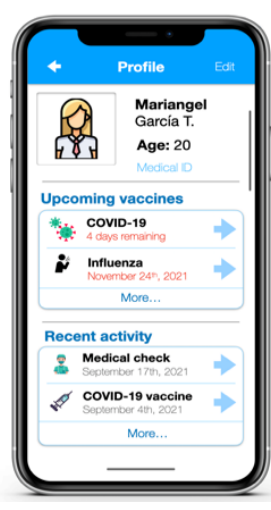

Figure 3. High school student profile showing user data and recent activity

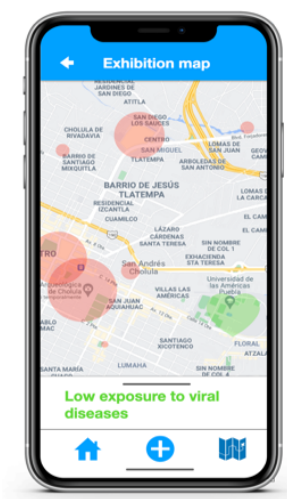

Figure 4. Contagious disease exposure map showing in red critical zones

\footnotetext{
2 Proto.io is an environment for creating prototypes, in this case for mobile devices, which allows us to design and present a draft of our future application, being able to use a multitude of tools and being. This platform can be found at the following link: https://proto.io/
}

The color of the area changes in size depending on the number of users who pass through there. In general, the areas that tend to grow the most are those public places where people tend to go the most. The user can interact with the map and make a pinch to zoom in or zoom out.

\section{Evaluation}

We conducted four different tests, one of the tests was applied to all participants to evaluate the functions shared by the three types of users that we handle in the application. The remaining three tests were divided for each of the three different user groups that we manage in the application. In total, there were forty-five participants in our evaluation, of which ten were teachers (five women and five men), fifteen were parents (seven women and eight men), and twenty were both high school and college students (ten women and ten men).

The test consisted of three steps that everyone should take: try to register in the application, check their medical records, and their most recent activity. Tests were also carried out that varied depending on the type of user. Thus, the father's test consisted of registering each of his children, registering any illness, and updating the medical record for any of the children he had registered. Subsequently, the student was asked to consult the exposure map, add a symptom, and show his QR code. Finally, the teacher was asked to consult the list of his students and pass attendance.

These tests were performed through the Zoom video conferencing tool, with which we showed the interfaces we designed using the proto. $\mathrm{io}^{2}$ tool. We showed the interface, and the user indicated the steps to perform the task we were asking. This was very useful because it allowed us to collect important information with which we knew better the design of our application. Thus, we were able to make improvements to have a better functionality of the application.

\section{Results and Discussion}

We conducted the evaluation and obtained information that allowed us to observe the aspects and vulnerabilities of the application to improve them. For the first three tasks applied to all users, the navigation was good in general since everyone could carry out the activity without difficulties. Participants suggested improving the interface design due to the tiny space to show specific user data such as his medical record and most recent activity.

With the individual tasks by type of user, starting with the parent's profile, navigation was straightforward, and the user could reach these windows quickly and in a few steps. As for the students, the majority suggested that the window showing the exposure map be larger because the size was tiny for some devices, which made their interaction with it difficult. Finally, the teachers did not have any problem while using the interfaces; however, some suggested adding more functionalities, such as classifying their students by gender and showing the means of transport that students usually use in their commute to school.

Something fundamental that we wanted to evaluate was knowing how friendly our interface was with the user. As shown in Figure 5, for most users who participated in our evaluation, it was 
easy to use the application, which is good since it allows the user to know the application's functionalities in a friendly way.

Thanks to the fact that users could become familiar with the interface quickly, the learning curve is reduced, allowing the user to use the application correctly and quickly. The above indicates that our application is intuitive and easy to use; essential aspects while using a mobile application.

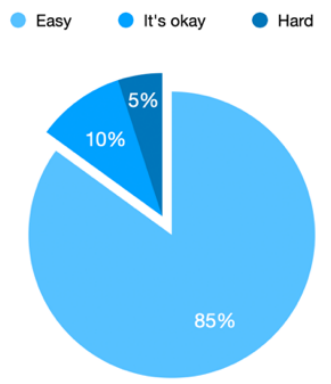

\section{Figure 5. Shows the level of difficulty that the user had when interacting with the application}

One aspect that is important to mention is that, during the usability tests, one of the users expressed: "if they had created this application before, the COVID-19 pandemic would not have existed", which makes us think about the usefulness of the application. The concept of utility refers to the design of the application, which must be understood to be original and aimed at meeting a need for use that the user has. Therefore, it is necessary to take it into account to provide a better user experience.

\section{Conclusion and Future work}

Applying the User-Centered Design (UCD) methodology and taking inspiration from technologies developed during the onset of the COVID-19 pandemic, we proposed the Digital Disease Tracker that allows educational institutions to better control the health status of their population. With this proposal, there is a solution accessible to most people who have a smartphone. It is inexpensive since it is not necessary to purchase additional equipment to use the application.

The design is thought to be simple, straightforward, and complete without the user spending a lot of time learning how to use the platform. In addition, the application is designed to adapt to new diseases that may arise in the future, and if so, it allows the critical places where the first cases began to appear in a faster way.

In the future, the authors recommend that the system be implemented for both Android and iOS platforms, which are the predominant operating systems on mobile devices. It is also suggested that the needs of schools be further analyzed to continue complementing the application and to continue carrying out evaluations that allow its improvement.

Likewise, another important aspect that we will consider for future work is privacy-implementing a section so that users can specify what data we can show in the application, always to protect user information. Given that article 16 of the Political Constitution of the United Mexican States establishes that "everyone has the right to the protection of their data, as well as to access, rectify and cancel and express their opposition to the treatment or use thereof by third parties," hence the desire to integrate this functionality to the mobile application [4].

\section{References}

[1] Albornoz, M. C. (2014, October). Diseño de interfaz gráfica de usuario. In XVI Workshop de Investigadores en Ciencias de la Computación.

[2] Annis, T., Pleasants, S., Hultman, G., Lindemann, E., Thompson, J. A., Billecke, S., ... \& Melton, G. B. (2020). Rapid implementation of a COVID-19 remote patient monitoring program. Journal of the American Medical Informatics Association, 27(8), 1326-1330.

[3] Cañedo Andalia, R., Ramos Ochoa, R. E., \& Guerrero Pupo, J. C. (2005). La Informática, la Computación y la Ciencia de la Información: una alianza para el desarrollo. Acimed, 13(5), 1-1.

[4] Constitución Política de los Estados Unidos Mexicanos [Const]. Art. 16. February 5, 1917 (Mexico).

[5] Datta, P. K., Liu, F., Fischer, T., Rappaport, J., \& Qin, X. (2020). SARS-CoV-2 pandemic and research gaps: Understanding SARS-CoV-2 interaction with the ACE2 receptor and implications for therapy. Theranostics, 10(16), 7448.

[6] Diseño Centrado en el Usuario (DCU). September 16th, 2021, de NSU web site: http://www.nosolousabilidad.com/manual/3.htm

[7] Kondylakis, H., Katehakis, D. G., Kouroubali, A., Logothetidis, F., Triantafyllidis, A., Kalamaras, I., \& Tzovaras, D. (2020). COVID-19 mobile apps: a systematic review of the literature. Journal of medical Internet research, 22(12), e23170.

[8] North, F., \& Chaudhry, R. (2016). Apple healthkit and health app: patient uptake and barriers in primary care. Telemedicine and e-Health, 22(7), 608-613.

[9] Stentsenko, R. (2019). Interface Essentials. Human Interface Guidelines. https://developer.apple.com/design/humaninterface-guidelines/ios/overview/interface-essentials

[10] Veale, M. (2020). Privacy is not the problem with the AppleGoogle contact-tracing toolkit. The Guardian.

[11] World Bank. (2021, January 22). Mitigate the impacts of COVID-19 on education around the world. https://www.bancomundial.org/es/news/immersivestory/2021/01/22/urgent-effective-action-required-to-quellthe-impact-of-covid-19-on-education- all over the world

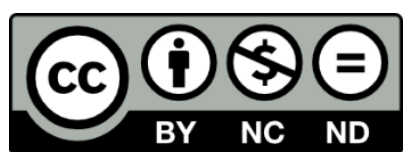

(C) 2021 by the authors. This work is licensed under the Creative Commons AttributionNonCommercial-NoDerivatives 4.0 International License. To view a copy of this license, visit http://creativecommons.org/licenses/by-nc-nd/4.0/ or send a letter to Creative Commons, PO Box 1866, Mountain View, CA 94042, USA. 